\title{
Effect of Hard Segment Molecular Weight on Dilute Solution Properties of Ether Based Thermoplastic Polyurethanes
}

\author{
K. W. Lem ${ }^{1,2, *}$, J. R. Haw ${ }^{3}$, S. Curran ${ }^{4}$, S. E. Sund ${ }^{1}$, C. Brumlik ${ }^{2}$, G. S. Song ${ }^{5}$, D. S. Lee ${ }^{5}$ \\ ${ }^{1}$ SuperLearning International, LLC, NJ, USA \\ ${ }^{2}$ Nanobiz, LLC, NJ, USA \\ ${ }^{3}$ Department of Materials Chemistry and Engineering, Konkuk University, Seoul, Republic of Korea \\ ${ }^{4}$ Boston Scientific, MA, USA \\ ${ }^{5}$ Department of Chemical Engineering, Chonbuk National University, Chonju, Republic of Korea \\ *Corresponding Authors: kwlem2001@yahoo.com
}

Copyright (C) 2013 Horizon Research Publishing All rights reserved.

\begin{abstract}
A systematic study was conducted on the effect of hard segment molecular weight (or length) on solution and bulk properties of ether based thermoplastic polyurethanes (TPUs). The purpose of this study is to provide a roadmap to deliver the desired end-use performance of a polyurethane product based on the optimal design of the starting materials. In this paper, we report our findings on the effects of hard segment molecular weight on properties of a dilute solution of TPUs in N, N-dimethyl formamide (DMF). The molar feed was used to determine the molecular weight of the hard segment. Then, the weight fraction of the hard segment is determined by calculating the ratio of the molecular weight of the hard segment to the number average molecular weight of the TPU determined by Gel Permeation Chromatography. It was found at low hard segment weight fraction there is a significant impact on the weight average molecular weight and molecular weight distribution, intrinsic viscosity, critical concentration, hydrodynamic diameter, polymer-solvent interaction parameter and second virial coefficient. However, at high weight fractions at around 0.4, the impact is minimal. Furthermore, the weight fraction has a minimal impact on number average molecular weight, and the expansion parameter in the Flory-Huggins analysis.
\end{abstract}

Keywords Thermoplastic Polyurethanes (TPUs), Synthesis, Flory-Huggins Analysis, and Dilute Solution Properties

\section{Introduction}

Polyurethane is one of the most diversified traditionaland nano-structured polymers known. Its structure-property relations have provided critical contributions in the development of many useful devices and applications, ranging from automotive tires, bumpers to biomedical implants such as cardiovascular devices and tissue replacement materials. Polyurethane synthesis can be conducted in solution, emulsion, or bulk polymerization, with or without chemical crosslinking. Tuning surface and bulk properties of a polyurethane material by means of hydrophilic and hydrophobic modifications, chemical functionality can be engineered into the main chain and side groups which have made it one of the most indispensable classes of polymers for applications in bulk and coatings use. The performance of polyurethanes depends on its chemical composition, segmental properties and the extent of hydrogen bonding. Intramolecular rigidity is a direct result of chemical bonding in terms of composition of chain structure, branching, and crosslinking. Physical bonding gives rise to intermolecular rigidity from degree of hard segment, crystallinity, and hydrogen bonding.

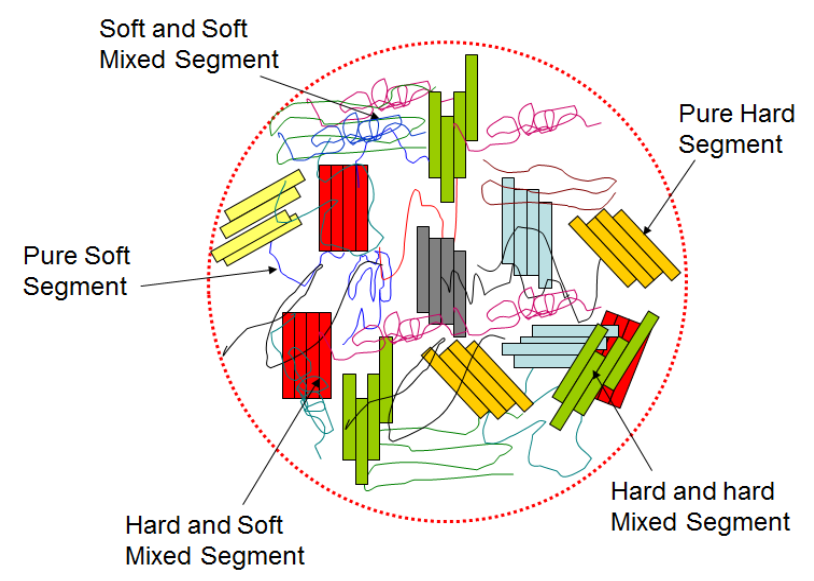

Figure 1. A Schematic Diagram for Hard and Soft Segment Morphology

A polyurethane material is composed of hard and soft 
segments as illustrated in Fig. 1. The hard segment contributes "plastic" properties such as tensile strength, tear strength, chemical resistance and high-temperature performance. Additional hydrogen bonding from the urethane group further increases the plastic properties and reduces intermolecular motion.

The soft segment contributes "elastomeric" properties such as hardness, compression and tension set, flexibility, and low-temperature performance.

Five potential morphologies are illustrated in the segmented polyurethane as seen in Fig. 1:

1) pure hard segment,

2) pure soft segment,

3) soft segment and soft segment mixing,

4) hard segment and hard segment mixing,

5) hard and soft segment mixing.

These hard and soft segments play a critical role in determining the properties at the nano- or micro-scale in the solid state. The intramolecular and intermolecular forces developed by these segmented morphologies control end use properties. In the past, much effort has focused on utilizing the effect of these segmented morphologies on annealing and changing chemical compositions. The most popular characterization methods have been rheological characterization [1-4]; differential scanning calorimetry [5-17]; SAXS [11-17], gel permeation chromatography and spectroscopy $[1,11-18]$.

Figure 2 gives a landscape of polyurethane applications in the mature, emerging, and developing market based on the relations between intramolecular and intermolecular rigidity.

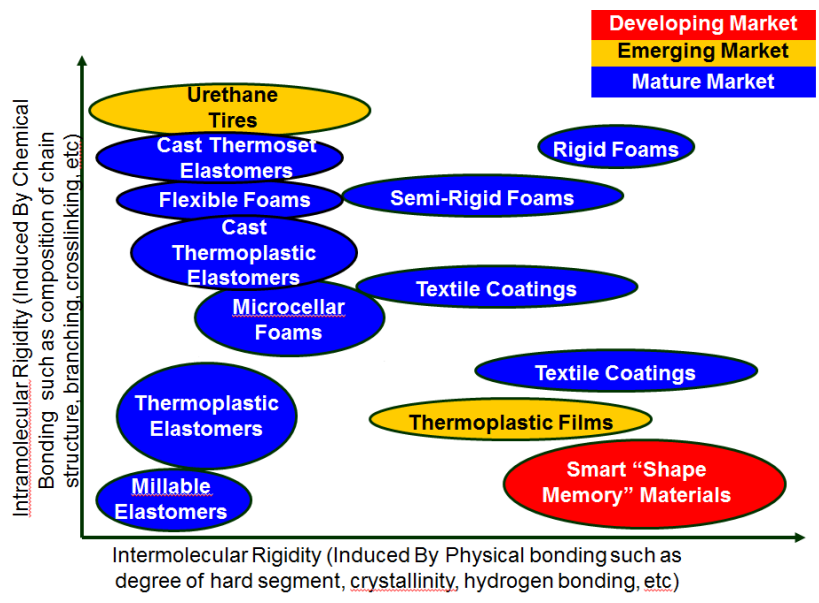

Figure 2. Effect of Polyurethane Properties on Applications (After Szycher, 1988; Zdrahala and Zdrahala, 1999) [19-20]

Most of the applications for polyurethanes are mature markets as seen in Figure 2. Szycher [19], Zdrahala and Zdrahala [20] have given more in-depth reviews, particularly in the area of biomedical applications.

Recently, polyurethanes have found increasing commercially importance in emerging and developing markets in tire and smart material applications. Because of their unusual chemical compositions and microstructure, polyurethanes have met some of the current needs in tire applications. Rubber tires often wear, cut, and tear faster than those made of polyurethanes because they have a softer tread surface than polyurethanes, making them less durable. Polyurethanes also have a lower rolling resistance than rubbers. This increases the efficiency of electric power vehicles and hybrid cars. Polyurethanes can be stimulus-active by adjusting configuration of hard and soft segments during a stimulus cycle. Shape memory stimulus-active materials have found applications in many intelligent materials and devices such as sensors/actuators, artificial muscles, smart stents, catheters, sutures, and smart textiles [21-22].

In general, a useful polyurethane product can be developed in two ways: top-down and bottom-up [23-26]. A top-down approach is essentially de-formulation of a urethane product to gain insight into its components for its make-up, materials and compositions. A bottom-up approach is the deliberate piecing together of starting materials to give rise to components and finally to build a urethane product.

Figure 3 gives a roadmap of top-down and bottom-up development of a urethane product using the value chain of "material - properties - processing - structure performance - applications". This roadmap helps to identify the unmet needs from materials to/from applications in the polyurethane product development and manufacture. Lem and his team have found this roadmap very useful in their design of eco-products, research and development of nanosilvers, nano zinc oxides, and transparent hybrids for consumer and biomedical applications [23-35].

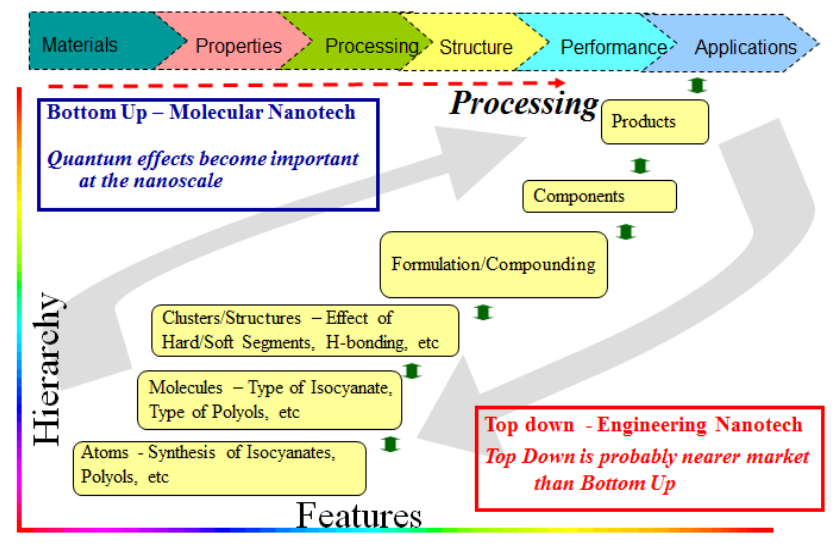

Tools to Identify the Unmet Needs from Materials to Applications

Figure 3. Top-Down and Bottom-Up Approach in Development of a Polyurethane Product [23-35]

Many useful components in polyurethane based devices are made from liquids, in the form of solution, dispersion, emulsion, or suspension. As a polyurethane film deposits from solution, its end-use properties depend strongly on its solution properties. Selection of a solvent is one of the most important factors in determining the processing and performance of polyurethane films. It is well established that different casting solvents bring about different film 
structures in term of aggregation and conformation which affect their end-use performance [36].

In a typical viscoelastic analysis, the storage modulus, $G^{\prime}$ (the elastic component), is a measure of the energy stored in the measured material, whereas the loss modulus, G" (the viscous component), is a measure of the energy dissipated as heat in the measured material, and $\tan \delta$ is the ratio of G" to $\mathrm{G}^{\prime}[37,38]$.

The volume fraction of polymer in the film increases with increasing drying temperature (and/or time) when a polymer film is cast from solution. The viscoelastic behavior of the polymer film changes from viscous behavior (where $G^{\prime \prime}>G^{\prime}$ in dilution solution) to elastic (where G' > G') behavior during the drying process. Finally solidification or gelation occurs as the film is formed. Figure 4 gives a plot of effect of volume fraction of polymer in solution on dynamic moduli (G', G'). There are two volume fractions of a polymer in solution of interest in Figure 4: (a) the volume fraction $\phi G^{\prime \prime}=G^{\prime}$ (when $\tan \delta=1$ at $\left.G^{\prime}=G^{\prime}\right)$, and the volume fraction $\phi_{\mathrm{GEL}}$ at "gel point" where the film is formed.

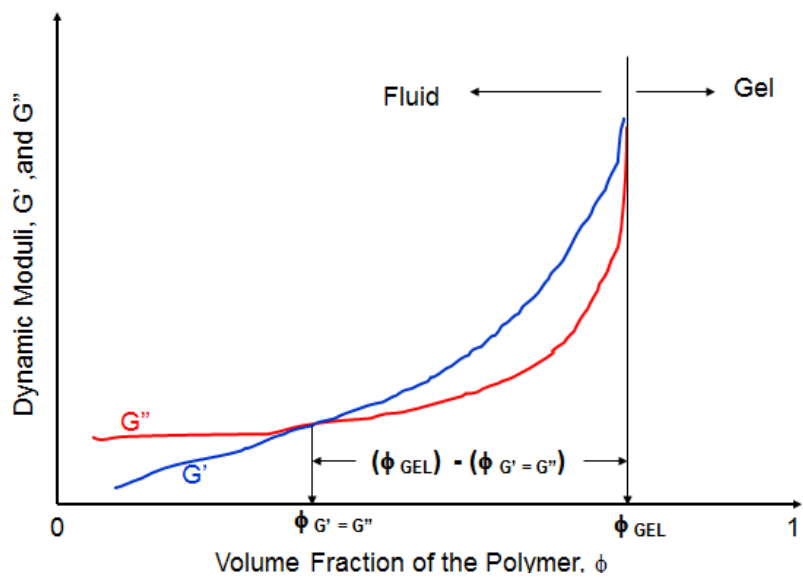

Figure 4. Effect of Volume Fraction of Polymer in Solution $(\phi)$ on Dynamic Moduli (G', G’) (After Prestidge and Tadros, 1988) [39]

Prestidge and Tadros [39] used the same approach in their study of viscoelastic properties of aqueous concentrated polystyrene latex dispersions. Flickinger et al. [40] reported that the volume fraction of polyurethane in these two regions $\left(\phi_{\mathrm{G}}{ }^{\prime}=\mathrm{G}\right.$, and $\left.\phi_{\mathrm{GEL}}\right)$ occurs in aqueous dispersion dependant on chemical composition, solvent/medium, ionic strength, and particle size of the urethane latex.

Similarly, the region in between these two regions (i.e., the difference between $\phi_{\mathrm{GEL}}$ and $\phi_{\mathrm{G}^{\prime}=\mathrm{G}^{\prime}}$ ) is expected to be dependent on chemical composition, solvent/medium, ionic strength, and particle size of the urethane latex.

Similarly, the region in between these two regions (i.e., the difference between $\phi_{\mathrm{GEL}}$ and $\phi_{\mathrm{G}^{\prime}=\mathrm{G}^{\prime}}$ ) is expected to be dependent on chemical composition, solvent/medium, ionic strength, and particle size of the urethane latex.

This approach has been used in the study of gelation of a thermosetting polymer during cure. $G$ ' increases with an increase in molecular weight and it rises even more rapidly until G' and G' converge. After G' exceeds G', both approach a very large value at the incipient gel point. Finally G' becomes infinite and G' achieves a maximum $[37,41]$. The cross-over point when $G^{\prime \prime}=G^{\prime}$ is commonly considered as a gelation point $[37,38,41,42]$.

Unlike thermoplastics, it is clear from Fig. 4, the time at the crossover point $(\tan \delta=1)$ as gel time is premature in the curing of a thermosetting polymer. It may be impossible to measure the exact time at the extent of reaction $\left(\alpha_{\mathrm{G}^{\prime \prime}=\mathrm{G}^{\prime}}\right)$

Unlike thermoplastics, it is clear from Figure 4, the time at the crossover point $(\tan \delta=1)$ as gel time is premature in the curing of a thermosetting polymer. It may be impossible to measure the exact time at the extent of reaction $\left(\alpha_{G^{\prime \prime}=G^{\prime}}\right)$ at which $G^{\prime \prime}=G^{\prime}$, to that of the extent of reaction $\left(\alpha_{\mathrm{GEL}}\right)$, at which the gelation occurs. This is because the rate of curing is extremely fast at the incipient gel point, and it is highly exothermic without proper temperature control. Sperling [38] asserted that the time at which $\tan \delta=1$ should be independent of frequency and temperature since the gelation point is a material property. Han and Lem [41] found, in their curing studies of vinyl and unsaturated polyester resin, the time at $\tan \delta=1\left(\mathrm{t}_{\tan \delta=1}\right)$ is relatively insensitive to frequency, but is strongly affected by the curing temperature.

\section{Approach of the Study}

Many polyurethane based consumer and biomedical products are made in a liquid form such as solution, dispersion, emulsion, or semi-liquid gels. The purpose of this study is to provide a roadmap to develop the desired polyurethane product based on the optimal use of the starting materials using the concepts illustrated in Figures 3 and 4 [23-35, 39].

This roadmap in Figure 5 provides a bottom-up approach to study the effect of hard segment length (i.e., molecular weight) on properties of a polyurethane material from a very dilute solution to bulk [24-26].

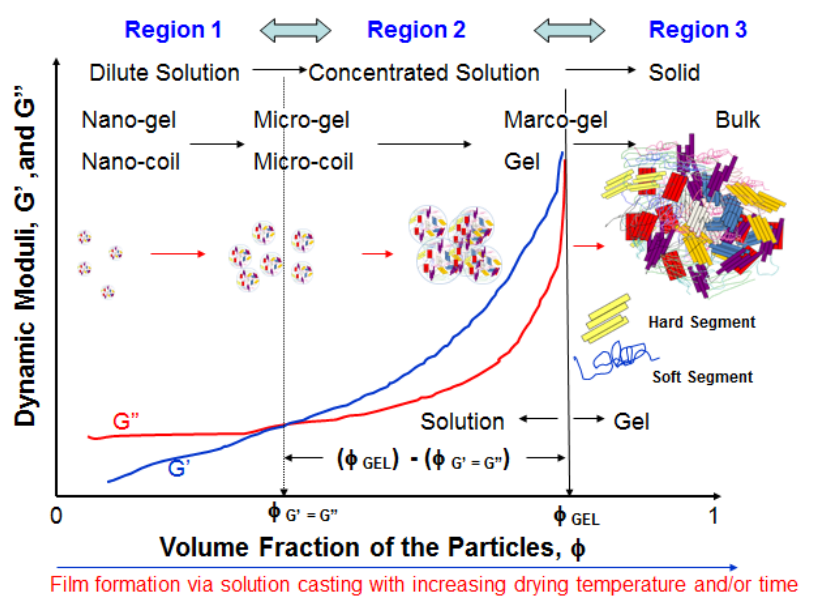

Figure 5. Experimental Approach to Study the Effect of Hard Segment 
The three regions seen in Figure 5 have been used with $\phi$ $\mathrm{G}^{\prime \prime}=\mathrm{G}$, and $\phi_{\mathrm{GEL}}$ as dividing points [24-26].

Region $1\left(\phi<\phi_{G^{\prime \prime}=G^{\prime}}\right)-$ The size and the shape of polyurethane molecules are expected to be extremely small. They may exist in the particle form of nano-coils or nano-gels. The morphology and the structure of these nano-scaled polyurethane particles are determined primarily by their chemical compositions and the nature of the hard and soft segments as illustrated in Fig. 1. In this region, the polymer fluid (in the form of solution, suspension, and emulsion) is often transparent because the wavelength of the scattered light is longer than the size of the polyurethane particles in the region. As the polymer concentration increases, the solution becomes more structured and particlesize increases approaching Region 2.

Region $2\left(\phi_{\mathrm{G}^{\prime \prime}=\mathrm{G}^{\prime}} \leq \phi<\phi_{\mathrm{GEL}}\right)-$ With the increasing polymer concentration during drying, the particles in solution become increasing "structurally complex". The size and shape of the polyurethane particles become larger by the coalescing of several nanosized polyurethane particles. The size may be no longer in the nano-scale but is rather in the micro-scale range. The morphology and the structure of these micro-scaled polyurethane particles are determined primarily by the size and nature of the nano-scaled particles from Region 1.

Region $3\left(\phi \geq \phi_{\mathrm{GEL}}\right)$ - The film is becoming more and more "solid-like" as the drying process progresses. In the solid state, the shape of the polyurethane molecules is now well defined, in hard and soft segmented domains of a two-phase morphology on the micro-scale in the bulk. The size and nature of the micro-scaled particles from Regions 1 and 2 greatly impact the structure-property of these hard and soft segmented micro-domains in the bulk, which in turn impacts the end-use properties of the polyurethanes.

We have conducted a study to develop polyurethane polymers using this roadmap. In this paper, we report the highlights of our study on the effects of hard segment molecular weight on dilute solution properties in Region 1. Recently, we have reported the findings in our study on the effects of hard segment molecular weight on concentrated solution properties and on bulk properties in Regions 2 and $3[24,26]$.

\section{Dilute Solution Properties}

We have employed the experimental methods reported by Kok and Rudin [43-45], Qian et al. [36], and Shmakov [46] to determine the parameters of the solution properties such as intrinsic viscosities, critical concentration, interaction parameters, and the size of TPU molecules in Region 1 where $\phi<\phi_{\mathrm{G}^{\prime \prime}=\mathrm{G}^{\prime}}$.

Qian et al. [36], and Shmakov [46] have suggested that the intrinsic viscosity at $\theta$-condition can be estimated as follows:

$$
[\eta]_{\theta}=\frac{[\eta]\left[1-\exp \left(-\frac{c}{c^{*}}\right)\right]}{\frac{0.77^{3} \rho}{c^{*}}-\exp \left(-\frac{c}{c^{*}}\right)}
$$

where $\rho$ and $c^{*}$ are respectively the coil density and the critical concentration at which the polymer coils begin to overlap and are defined by:

$$
\rho=\frac{c}{\eta_{s p}}\left(1.25+0.5 \sqrt{56.4 \eta_{s p}+6.25}\right)
$$

and

$$
c^{*}=\frac{3 \varphi^{\prime}}{4 \pi N_{A}[\eta]}
$$

In Equations (2) and (3), $\eta_{\mathrm{sp}}$ is specific viscosity, $\phi^{\prime}$ is the Flory universal constant, which equals $3.1 \times 10^{24}$ when $[\eta]$ is expressed in $\mathrm{ml} / \mathrm{gm}$, and $\mathrm{N}_{\mathrm{A}}$ is Avogadro's number.

Using the intrinsic viscosities and the number average molecular weights of TPUs determined by gel permeation chromatography (GPC), we can estimate osmotic pressure of the TPU solutions using the following methods suggested by Kok and Rudin [43-45] as

$$
\frac{\pi}{c}=\frac{R T}{M_{n}}\left(1+A_{2}^{*} \frac{M_{n} c}{2}\right)^{2}
$$

where $\mathrm{A}_{2} *$ is given by

$$
A_{2}^{*}=\frac{16 \pi N_{A}[\eta]}{M_{n}\left(9.3 \times 10^{24}+4 \pi N_{A} c\left([\eta]-[\eta]_{\theta}\right)\right)}\left(1-\frac{[\eta]_{\theta}}{[\eta]}\right)
$$

Then, we can determine the second virial coefficient, $\mathrm{A}_{2}$, from the following definition and the plots shown in Fig. 11.

$$
\frac{\pi}{c}=R T\left(\frac{1}{M_{n}}+A_{2} c+A_{3} c^{2}+\cdots\right)
$$

The interaction parameter, $\chi$, can be obtained from the following;

$$
A_{2}=\frac{\frac{1}{2}-\chi}{\rho_{p}^{2} V_{s}}
$$

By assuming the TPU molecules are spherical in solution, the hydrodynamic radius $(\mathrm{RH})$ was estimated using Equation 8 by Flickinger et al. [40], and the hydrodynamic diameter is 2RH. where

$$
R_{H}=\left(0.3 \frac{M_{\Perp}[\eta]}{\pi N_{A}}\right)^{1 / 3}
$$

\section{Experimental}

\subsection{Polyurethanes Synthesis}


A segmented di-block thermoplastic polyurethane (TPU) is synthesized in this study, following the procedure and the analysis described by Kim and Lee [47] and Nguyen et al. [48]. TPU is a linear segmented block copolymer composed of soft segment and hard segment which undergo phase separation. Figure 6 provides an outline in the design of the segmented TPU used in this study.

A Hard and Soft Segmented Polyurethane Polymer

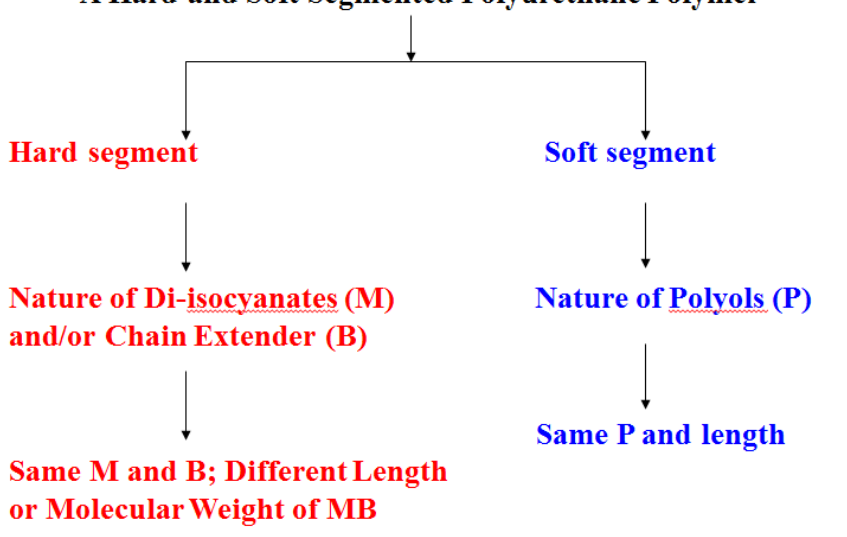

Figure 6. Design Outline for Segmented Diblock PU

The type and molecular weights of polyols determine the soft segment properties. Hard segment properties are determined by the type of diisocyanate and chain extender. Thus, TPU properties may be adjusted by the type of raw materials and the nano-/micro-phase separation in/between soft and hard segments. The starting materials for the diblock segmented TPU are given in Fig. 7.

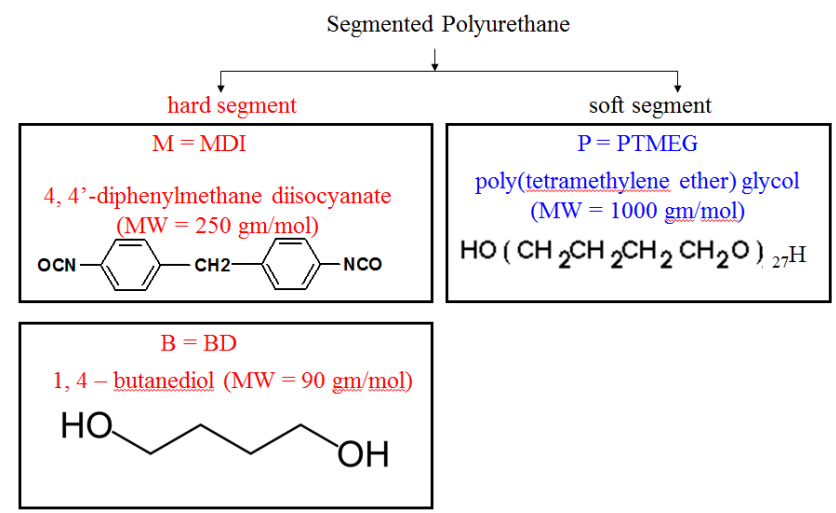

Figure 7. Starting Materials to Build the Segmented Diblock (PU $[47-48]$

A schematic diagram of a two-steps synthesis of the TPU is given in Fig. 8.

\subsubsection{Prepolymer Synthesis}

TPU was prepared by solution polymerization in $\mathrm{N}$, N-dimethylformamide (DMF: MW=73.09 gm/mol, density (a) $20 \mathrm{oC}=0.944 \mathrm{gm} / \mathrm{ml}$, molar volume $=77.43 \mathrm{ml} / \mathrm{mol}$ ). Poly (tetramethylene ether glycol) (PTMEG: $\mathrm{Mn}=1,000$ $\mathrm{gm} / \mathrm{mol}$ ) was reacted with various amounts of 4,4'-diphenylmethane diisocyanate (MDI: $\mathrm{MW}=250$ $\mathrm{gm} / \mathrm{mol}$ ) at $60 \mathrm{oC}$ for $90 \mathrm{~min}$ to prepare the prepolymer with terminal NCO groups.

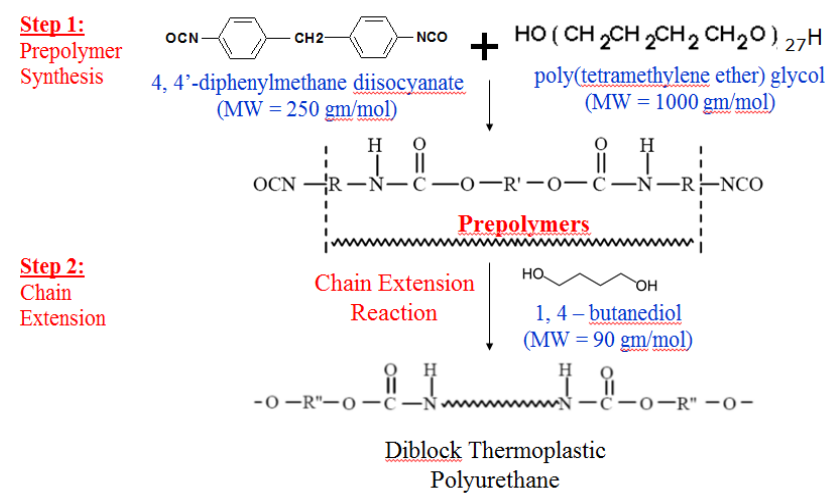

Figure 8. A Two-Steps Segmented Diblock Thermoplastic Polyurethane Synthesis [47-48]

\subsubsection{Chain Extension Reaction}

After the NCO content of the prepolymer was confirmed by back titration using $n$-dibutyl amine (ASTM D2572-80), the prepolymer was chain-extended in DMF by adding 1,4-butanediol (BD: $\mathrm{MW}=90 \mathrm{gm} / \mathrm{mol}$ ) and additional MDI at $60 \mathrm{oC}$ for 120 minutes. Both reactions were carried out under dry nitrogen atmosphere. Solid content of the final solution was $20 \mathrm{wt} \%$.

Table 1 gives sample codes and polymerization procedures to prepare TPUs with different segment structure in a two-step synthesis process. It is shown in Table 1 that for various TPUs, we have calculated the hard segment molecular weight based on the segment structure and molar feed. The molecular weight of the hard segment increases from TPUHS1 to TPUHS5 by systematically changing polymerization procedures.

Table 1. Sample codes and molar feed ratios for TPUs of various segment structures in a same chemical composition

\begin{tabular}{|c|c|c|c|c|c|c|c|}
\hline \multirow[t]{2}{*}{$\begin{array}{l}\text { Sample } \\
\text { code }\end{array}$} & \multicolumn{2}{|c|}{$\begin{array}{l}\text { Prepolymer } \\
\text { (1st step) }\end{array}$} & \multicolumn{2}{|c|}{$\begin{array}{c}\text { Chain Extension } \\
\text { (2nd step) }\end{array}$} & \multicolumn{2}{|c|}{ Typical Segment Stru } & \multirow{2}{*}{$\begin{array}{c}\text { Hard Segment } \\
\text { MW } \\
(\mathrm{gm} / \mathrm{mol})\end{array}$} \\
\hline & $\begin{array}{c}\text { Polyol } \\
\text { (PTMEG) }\end{array}$ & MDI & MDI & $\mathrm{BD}$ & Hard & Soft & \\
\hline $\mathrm{TPU}_{\mathrm{HS} 1}$ & 1 & 2 & - & 1 & $\mathrm{M}(\mathrm{BM})_{1}$ & $\mathrm{P}$ & 590 \\
\hline $\mathrm{TPU}_{\mathrm{HS} 2}$ & 1 & 1.5 & 0.5 & 1 & $\mathrm{M}(\mathrm{BM})_{2}$ & PMP & 930 \\
\hline $\mathrm{TPU}_{\mathrm{HS} 3}$ & 1 & 1.25 & 0.75 & 1 & $\mathrm{M}(\mathrm{BM})_{4}$ & $\mathrm{P}(\mathrm{MP})_{3}$ & 1610 \\
\hline $\mathrm{TPU}_{\mathrm{HS} 4}$ & 1 & 1.125 & 0.875 & 1 & $\mathrm{M}(\mathrm{BM})_{8}$ & $\mathrm{P}(\mathrm{MP})_{3}$ & 2970 \\
\hline $\mathrm{TPU}_{\text {HS5 }}$ & 1 & 1.0625 & 0.9375 & 1 & $\mathrm{M}(\mathrm{BM})_{16}$ & $\mathrm{P}(\mathrm{MP})_{3}$ & 5690 \\
\hline
\end{tabular}

\subsection{Characterization of TPU}

\subsubsection{Molecular Weight Measurement and Intrinsic Viscosity Measurement}

TPU molecular weights were measured via gel permeation chromatographgy (GPC, Spectra-Physics SP8800). Intrinsic viscosities of the TPUs were determined with an Ubbelodh viscometer at $25{ }^{\circ} \mathrm{C}$ to investigate interactions between 
TPUs and DMF.

\section{Results and Discussion}

\subsection{Molecular Weight Measurement}

The average molecular weights of TPUs determined by GPC and the weight fraction of the hard segment in the TPU are given in Table 2. We used the molar feed to determine the molecular weight of the hard segment as given in Table 1. The weight fraction of the hard segment is then the ratio of the molecular weight of the hard segment to the number average molecular weight of the TPU determined by GPC in Table 2 .

Table 2. Molecular Weights of the TPUs and Weight Fraction of Hard Segment Prepared by Different Polymerization Procedures

\begin{tabular}{|c|c|c|c|c|c|}
\hline \multirow{2}{*}{$\begin{array}{l}\text { Sample } \\
\text { Code }\end{array}$} & \multicolumn{3}{|c|}{ Molecular Weights } & \multirow{2}{*}{$\begin{array}{c}\text { Total Hard } \\
\text { Segment MW }\end{array}$} & \multirow{2}{*}{$\begin{array}{l}\text { Weight Fraction of } \\
\text { Hard Segment* }\end{array}$} \\
\hline & $\mathrm{M}_{\mathrm{n}}$ & $\mathrm{M}_{\mathrm{w}}$ & MWD & & \\
\hline $\mathrm{TPU}_{\mathrm{HS}}$ & 8,400 & 38,600 & 4.60 & 590 & 0.070 \\
\hline $\mathrm{TPU}_{\mathrm{HS} 2}$ & 7,700 & 43,400 & 5.64 & 930 & 0.121 \\
\hline $\mathrm{TPU}_{\mathrm{HS} 3}$ & 7,700 & 54,000 & 7.01 & 1610 & 0.209 \\
\hline TPU ${ }_{\text {HS4 }}$ & 6,600 & 56,400 & 8.55 & 2970 & 0.450 \\
\hline $\mathrm{TPU}_{\text {HS5 }}$ & 7,100 & 54,200 & 7.63 & 5690 & 0.801 \\
\hline
\end{tabular}

\subsubsection{Effect of Hard Segment Molecular Weight on TPU's} Molecular Weights and Distribution

Fig. 9 shows a plot of number average molecular weight $(\mathrm{Mn})$ and weight average molecular weight $(\mathrm{Mw})$ of the TPU as a function of weight fraction of hard segment. Figure 10 shows the molecular weight distribution (polydispersity index) vs. weight fraction of the hard segment.

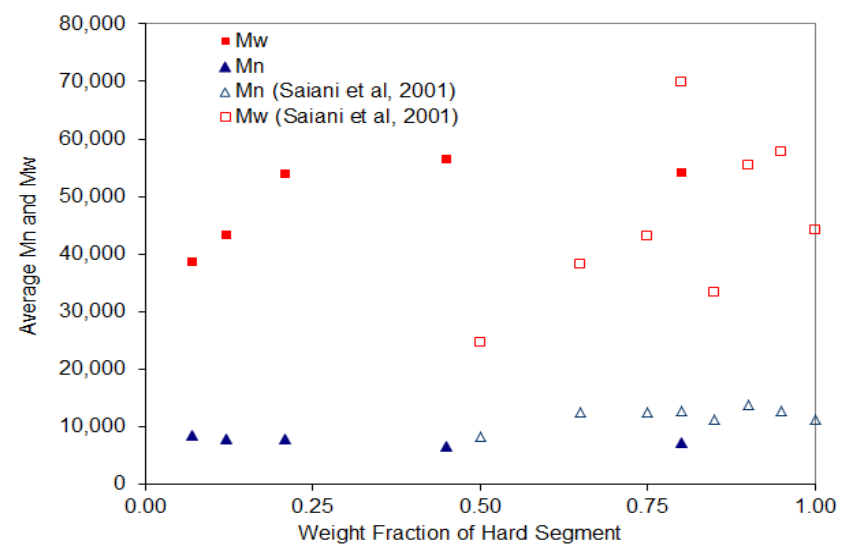

Figure 9. Average Molecular Weights vs. Weight Fraction of Hard Segment

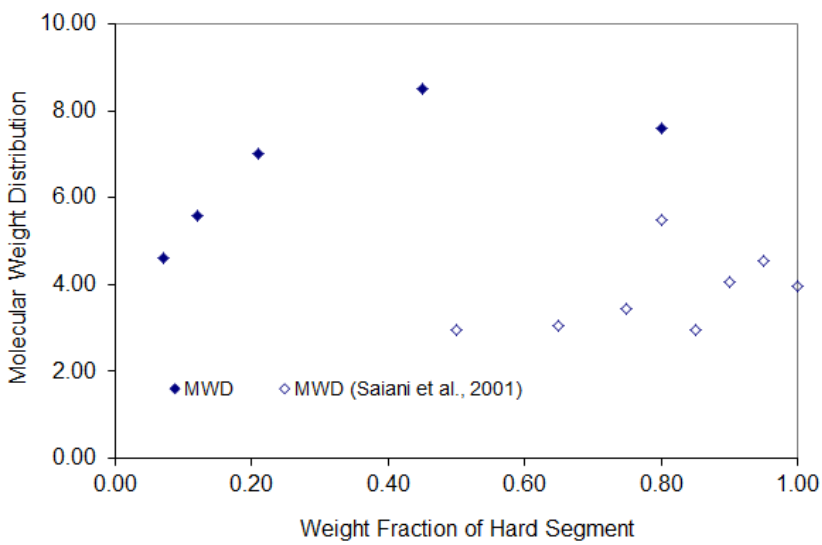

Figure 10. Molecular Weight Distribution vs. Weight Fraction of Hard Segment

Interestingly, the effect of increasing hard segment content has minimal influence on the number average molecular weight, but it has a significant impact on the weight average molecular weight to a certain degree. This impact levels off at about 0.4 weight fraction of the hard segment in the TPU. Consequently, the MWD showed a leveling off effect in Figure 10 at this same range.

Figs. 9 and 10 also give a comparison of the effect of hard segment molecular weight on average molecular weight and MWD for different chemical compositions of polyurethanes studied by Saiani et al. [5-7]. Unlike our urethane system, their TPU systems were made from a commercially available polypropylene oxide based polyol that was end-capped with ethylene oxide. This PPO-EO had an average molecular weight of 3700 . The polyisocyante used was 4, 4' methylene diphenyldiisocyanate and 2-methyl-1, 3-propanediol was used as a chain extender.

Similar to our study, the number average molecular weight reported by Saiani et al. [5-7] is insensitive to the weight fraction of the hard segment. Despite the significant data scatter, MWD in their studies (see Fig. 10) appears to increase as hard segment content increases. The limited rise in number average molecular weight with increasing hard segment molecular weight is intriguing and further research is needed to elucidate this finding. The impact of hard segment on MWD for TPUs may be used to enhance their processibility because a broader MWD usually improves extrusion and injection molding characteristics, increases green strength, and gives better surface appearance [37].

\subsection{Solution Properties of TPUs}

The parameters of the solution properties determined from Equations 1 to 8 and Fig. 11 are given in Table 3. The following is a discussion of the experimental findings on the effect of hard segment molecular weight on the solution properties. 


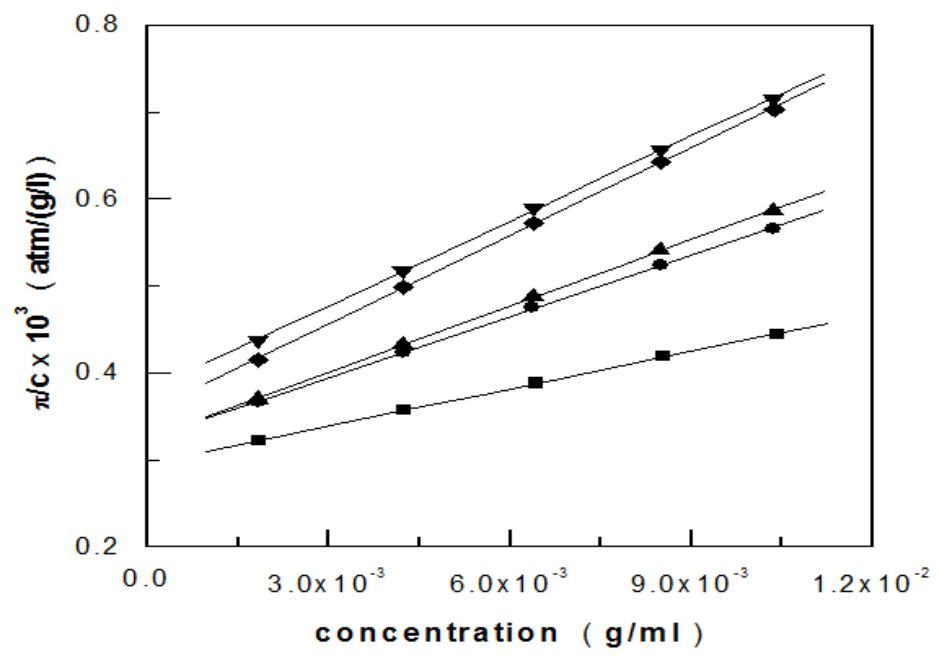

$\mathrm{TPU}_{\text {HS1 }} ;(\bullet) \mathrm{TPU}_{\text {HS2 }} ;(\boldsymbol{\Delta}) \mathrm{TPU}_{\mathbf{H S} 3} ;(\boldsymbol{\nabla}) \mathrm{TPU}_{\mathbf{H S} 4} ;(\bullet) \mathrm{TPU}_{\text {HS5 }}$

Figure 11. Reduced osmotic pressure $(\pi / \mathrm{c})$ estimated for different TPU solutions at $25^{\circ} \mathrm{C}$.

Table 3. Solution Properties of the Various TPUs in DMF at $25^{\circ} \mathrm{C}$

\begin{tabular}{|c|c|c|c|c|c|c|c|c|c|}
\hline $\begin{array}{c}\text { Sample } \\
\text { Code }\end{array}$ & $\begin{array}{c}\text { Fraction of } \\
\text { Hard } \\
\text { Segment }\end{array}$ & $\begin{array}{c}\mathrm{M}_{\mathrm{w},} \\
\mathrm{gm} / \mathrm{mol}\end{array}$ & MWD & $\begin{array}{c}{[\eta],} \\
\mathrm{ml} / \mathrm{gm}\end{array}$ & $\begin{array}{c}\mathrm{C}^{*} \\
\mathrm{gm} / \mathrm{ml}\end{array}$ & $\begin{array}{c}{[\eta]_{\theta},} \\
\mathrm{ml} / \mathrm{gm}\end{array}$ & $\mathrm{A}_{2}$ & $\chi$ & $\begin{array}{c}\text { Hydro- } \\
\text { dynamic } \\
\text { Diameter } \\
(\mathrm{nm})\end{array}$ \\
\hline TPU $_{\text {HS1 }}$ & 0.070 & 38,600 & 4.6 & 34.47 & 0.037 & 18.29 & 0.006 & -0.062 & 11.909 \\
\hline TPU $_{\text {HS2 }}$ & 0.121 & 43,400 & 5.6 & 42.24 & 0.029 & 19.10 & 0.009 & -0.419 & 13.252 \\
\hline TPU $_{\text {HS3 }}$ & 0.209 & 54,000 & 7.0 & 48.27 & 0.025 & 23.09 & 0.010 & -0.490 & 14.902 \\
\hline TPU $_{\text {HS4 }}$ & 0.450 & 56,400 & 8.5 & 53.64 & 0.023 & 25.82 & 0.013 & -0.772 & 15.660 \\
\hline TPU $_{\text {HS5 }}$ & 0.801 & 54,200 & 7.6 & 60.26 & 0.020 & 28.82 & 0.014 & -0.820 & 16.065 \\
\hline
\end{tabular}

Table 4. Intrinsic Viscosities of the Various TPUs in DMF at $25^{\circ} \mathrm{C}$

\begin{tabular}{|c|c|c|c|c|c|c|c|}
\hline $\begin{array}{c}\text { Sample } \\
\text { Code }\end{array}$ & $\begin{array}{c}\text { Weight } \\
\text { Fraction of } \\
\text { Hard Segment }\end{array}$ & $\begin{array}{c}\mathrm{M}_{\mathrm{w},} \\
\mathrm{gm} / \mathrm{mol}\end{array}$ & $\mathrm{MWD}$ & $\begin{array}{c}{[\eta],} \\
\mathrm{ml} / \mathrm{gm}\end{array}$ & $\begin{array}{c}{[\eta]_{\theta,}} \\
\mathrm{ml} / \mathrm{gm}\end{array}$ & {$[\eta] /[\eta]_{\theta}$} & $\left([\eta] /[\eta]_{\theta}\right)^{1 / 3}$ \\
\hline TPU $_{\text {HS1 }}$ & 0.070 & 38,600 & 4.6 & 34.47 & 18.29 & 1.88 & 1.235 \\
\hline TPU $_{\text {HS2 }}$ & 0.121 & 43,400 & 5.6 & 42.24 & 19.10 & 2.21 & 1.303 \\
\hline TPU $_{\text {HS3 }}$ & 0.209 & 54,000 & 7.0 & 48.27 & 23.09 & 2.09 & 1.278 \\
\hline TPU $_{H S 4}$ & 0.450 & 56,400 & 8.5 & 53.64 & 25.82 & 2.08 & 1.276 \\
\hline TPU & 0.801 & 54,200 & 7.6 & 60.26 & 28.82 & 2.09 & 1.278 \\
\hline
\end{tabular}




\subsubsection{Intrinsic Viscosities and Expansion Parameter}

The results of intrinsic viscosities of the various TPUs in DMF at $25^{\circ} \mathrm{C}$ are given in Table 4. Fig. 12 gives the plots of $[\eta]$ and $[\eta]_{\theta}$ as a function of weight fraction of hard segment. As seen in Fig. 12 and Table 4, both intrinsic viscosities increase with fraction of hard segment molecular weight, and at about 0.4 weight fraction of the hard segment, the effect levels off.

The relation between $[\eta]$ and $[\eta]_{\theta}$ can be further developed using the definition of intrinsic viscosity of dilute linear polyurethane solutions in a theta solvent and a non-theta solvent as expressed by Eqs. (9) and (10), respectively [38].

$$
\begin{aligned}
{[\eta]_{\theta} } & =K_{\theta}[\mathrm{M}]^{1 / 2} \\
{[\eta] } & =\mathrm{K}[\mathrm{M}]^{1 / 2} \alpha^{3}
\end{aligned}
$$

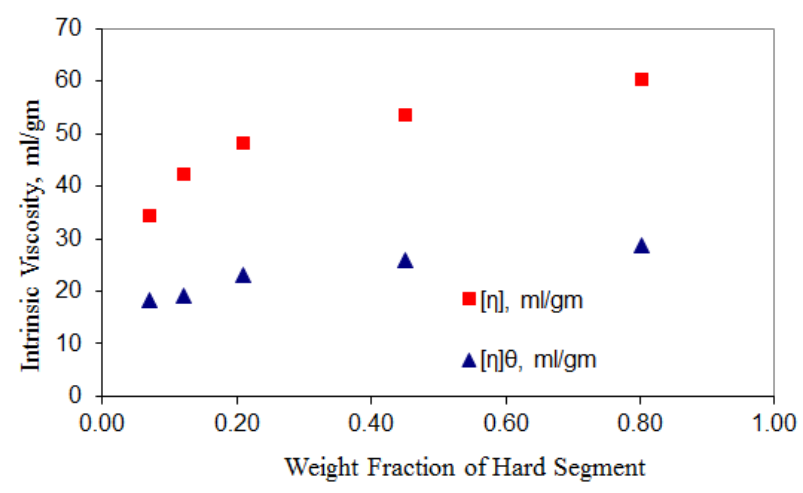

Figure 12. Intrinsic Viscosities vs. Weight Fraction of Hard Segment

$\mathrm{K}$ is a constant for a given polymer and is independent of solvent and molecular weight. $\mathrm{K} \theta$ is a constant that can be related to the root-mean-square end to end distance of the polymer chain.

According to Beachell and Peterson [49], the factor $\alpha$ defined in Equations 10 and 11 is the intrinsic viscosity expansion parameter and is a measure of the long-range interaction due to perturbation of the polymer coil relative to the unperturbed dimensions of the polymer molecules. The intrinsic viscosity expansion parameter can be thought of as a measure of molecular expansion due to the effect of solvent on the polymer configuration.

$$
\alpha=\left([\eta] /[\eta]_{\theta}\right)^{1 / 3}
$$

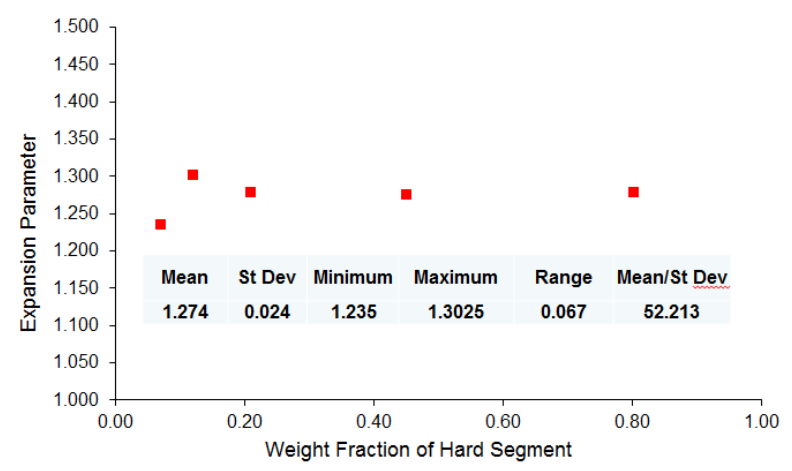

Figure 13. Expansion Parameter vs. Weight Fraction of Hard Segment
Fig. 13 gives a plot of expansion parameters as a function of weight fraction of hard segment along with a statistical analysis. Interestingly, the results of a statistical analysis even for 5 data points seem to suggest that the weight fraction of the hard segment has very little impact on the expansion parameter when the DMF (a good solvent for TPUs) is used as a solvent.

\subsubsection{Critical Concentration and Hydrodynamic Diameter}

Fig. 14 shows a plot of critical concentration, and Fig. 15 gives a plot of hydrodynamic diameter, as a function of weight fraction of hard segment, respectively.

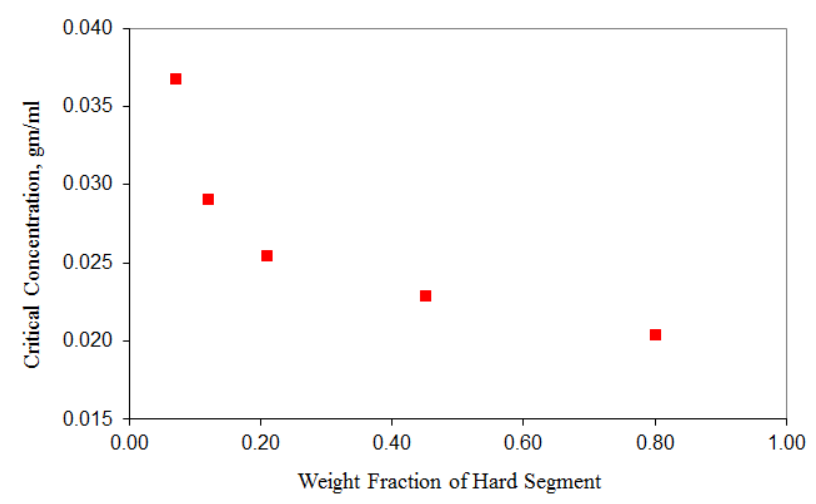

Figure 14. Critical Concentration vs. Weight Fraction of Hard Segment

The critical concentration is defined as the concentration of polymer at which the polymer coils begin to overlap each other [36]. Unlike the expansion parameter, the critical concentration decreases with the hydrodynamic diameter. This increase in size of hydrodynamic diameter with weight fraction of the hard segment is very pronounced at low weight fraction of hard segment until it reaches a constant value at about 0.4 weight fraction of the hard segment.

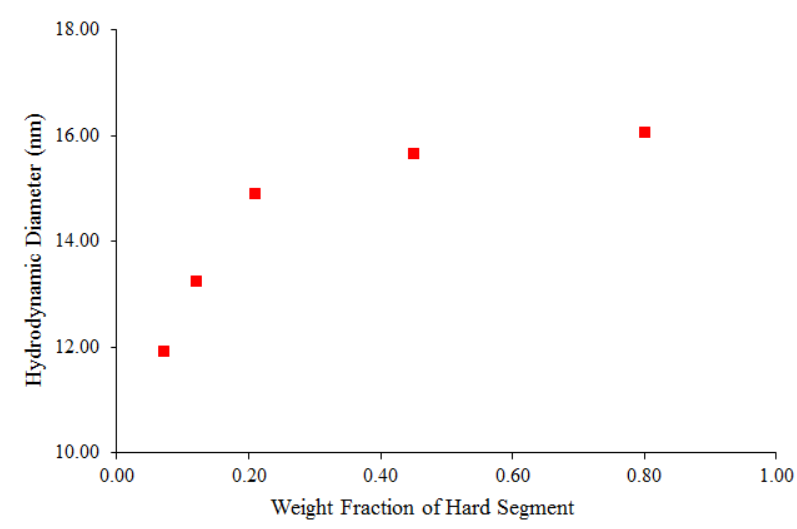

Figure 15. Hydrodynamic Diameter vs. Weight Fraction of Hard Segment

\subsubsection{Interaction Parameter and Second Virial Coefficient}

The polymer-solvent interaction parameter $(\chi)$, based on the Flory-Huggins analysis, is an important parameter to characterize the stability of a polymer solution. A value of $\chi$ $<0.5$ is the general criterion for polymer solubility for infinitely dilute solutions of a very high molecular weight 
polymer [45]. A negative $\chi$ implies $\Delta$ Gmix becomes more negative which in term suggests a favorable interaction. With increasing hard segment molecular weight, there are more intermolecular interactions and entanglements due to hydrogen bonding from the urethane groups. Therefore, it is an unsurprising observation that the hard segment molecular weight impacts the value of $\chi$ more significantly than any other solution properties tabulated in Table 3 .

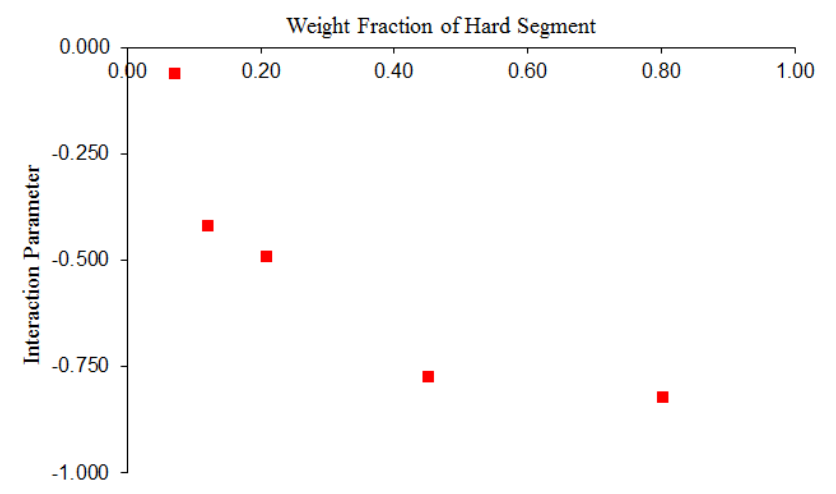

Figure 16. Interaction Parameters vs. Weight Fraction of Hard Segment

When the interaction parameter $(\chi)$ is large and negative, the second virial coefficient is large and positive, as in the case shown in Figs. 16 and 17. Similar to the results for critical concentration and hydrodynamic diameter, they change rapidly with increasing weight fraction of hard segment until a value of about 0.4. Furthermore, as illustrated in Fig. 11, the slope of osmotic pressure $(\pi / \mathrm{c})$ vs. c is increasing and positive with increasing weight fraction of hard segment. This in turn implies that DMF is a good solvent for this TPUs system; i.e. the higher the slope, the better the solvent.

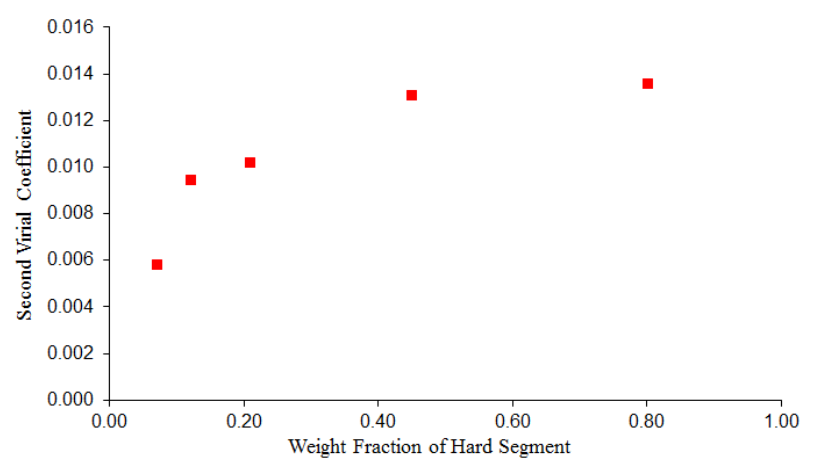

Figure 17. Second Virial Coefficient vs. Weight Fraction of Hard Segment

\section{Conclusions}

In this paper, we report the highlights of our study on the effects of hard segment molecular weight on the properties of a dilute solution of TPUs in N, N-dimethyl formamide (DMF) in Region 1. Fig. 18 gives a summary of the effect of critical hard segment concentration on functional properties in Region 1.

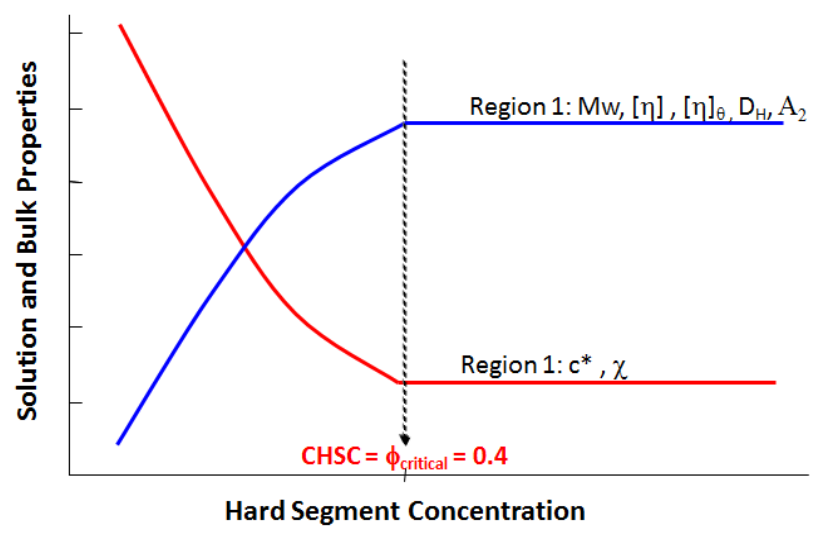

Figure 18. Summary of the effect of critical hard segment concentration on functional properties in Diluted Solution (Region 1)

At this juncture, it is worth noting that similar findings were reported in microemulsion systems [50]. The onset of critical micelle concentration (CMC) of surfactant has been observed by a sudden change in measured functional properties of solution that is found at characteristic surfactant concentration. For example in surface tension, below the CMC the surfactant adsorbs on the surface and decreases surface tension. The more surfactant we have below CMC the less surface tension. Above CMC the onset of micelles formation begins. All surfactant added in excess of the CMC incorporate into the micelles. Therefore surface tensions remain the same as at CMC [50].

At low values, we found that the weight fraction of the hard segment strongly affects the weight average molecular weight $\left(\mathrm{M}_{\mathrm{w}}\right)$ and molecular weight distribution (MWD), intrinsic viscosities $([\eta])$, critical concentration $\left(\mathrm{c}^{*}\right)$, hydrodynamic diameter $\left(\mathrm{D}_{\mathrm{H}}\right)$, polymer-solvent interaction parameter $(\chi)$ and second virial coefficient $\left(\mathrm{A}_{2}\right)$.

The impact levels off at about 0.4 weight fraction of the hard segment in the TPUs. Consequently, the MWD shows a leveling off effect at 0.4 weight fraction. Similar results found in number average molecular weight were reported by Saiani et al. [5-7].

Both intrinsic viscosities increase with fraction of hard segment molecular weight, and at about 0.4 weight fraction of the hard segment, the effect levels off.

The weight fraction of the hard segment has very little impact on the expansion parameter when the DMF (a good solvent for TPUs) is used as a solvent. But the critical concentration decreases with the hydrodynamic diameter. This increase in size of hydrodynamic diameter with weight fraction of the hard segment is very pronounced at low weight fractions of hard segment until it reaches a constant value at about 0.4 weight fraction of the hard segment.

Similar to the results for critical concentration and hydrodynamic diameter, they change rapidly with increasing weight fraction of hard segment until a value of about 0.4. 
We have reported recently the similar findings in our study on the effects of hard segment molecular weight on concentration solution properties in Region 2 and on bulk properties in Region 3 [24, 26].

\section{Acknowledgements}

This study was supported by R \& D Center for Valuable Recycling (Global Top Environmental Technology Development Program funded by Ministry of Environment. (Project No. 11-A04-OD).

\section{REFERENCES}

[1] P. J. Yoon and C. D. Han, "Effect of thermal history on the rheological behavior of thermoplastic polyurethanes,", Macromolecules, 33, 2171-2183 (2000)

[2] S. Velankar, S.L. Cooper, "Microphase separation and rheological properties of polyurethane melts. Part 1: Effect of block length", Macromolecules, 31, 9181-9192 (1998)

[3] S. Velankar, S.L. Cooper, "Microphase separation and rheological properties of polyurethane melts. Part 3: Effect of block incompatibility on the viscoelastic properties", Macromolecules, 33, 382-394 (2000)

[4] S. Velankar, S.L. Cooper, "Microphase separation and rheological properties of polyurethane melts. Part 2: Effect of block incompatibility on the microstructure", Macromolecules, 33, 395-403 (2000)

[5] A. Saiani, A. Novak, L. Rodier, G. Eeckhaut, J.-W. Leenslag, and J. S. Higgins, "Origin of Multiple Melting Endotherms in a High Hard Block Content Polyurethane. Effect of Annealing temperature," Macromolecules, 40, 7252-7262 (2007)

[6] A. Saiani, W. A. Daunch, H. Verbeke, J.-W. Leenslag, and J. S. Higgins, "Origin of Multiple Melting Endotherms in a High Hard Block Content Polyurethane. 1. Thermodynamic Investigation," Macromolecules, 34, 9059-9068 (2001)

[7] A. Saiani, C. Rochas, G. Eeckhaut, W. A. Daunch, J.-W. Leenslag, and J. S. Higgins, "Origin of Multiple Melting Endotherms in a High Hard Block Content Polyurethane. 2. Structural Investigation," Macromolecules, 37, 1411-1421 (2004)

[8] S. Velankar, J. Pazos, S.L. Cooper, "High performance UV-curable urethane acrylates via deblocking chemistry", J. Appl. Polym. Sci., 62, 1361-1376 (1996)

[9] J. W. C. van Bogart, D. A. Bluemke, and S. L. Cooper, "Annealing-induced morphological changes in segmented elastomers," Polymer, 22(10), 1428-1438, (1981)

[10] E. Govorcin Bajsic, V. Rek, A. Sendijarevic, V. Sendijarevic and K. C. Frisch, "DSC Study of Morphological Changes in Segmented Polyurethane Elastomers," Journal of Elastomers and Plastics, 32, 162 (2000)

[11] L. M. Leung and J. T. Koberstein, "Small-Angle Scattering Analysis of Hard-Microdomain Structure and Microphase
Mixing in Polyurethane Elastomers," Polymer Science: Polymer Physics Edition, Vol. 23, 1883-1913 (1985)

[12] J. T. Koberstein and A. F. Galambos, "Multiple Melting in Segmented Polyurethane Block Copolymers," Macromolecules 25, 5618-5624 (1992)

[13] J.T. Koberstein, A. F. Galambos, and L. M. Leung, "Compression-Molded Polyurethane Block Copolymers. 1. Microdomain Morphology and Thermomechanical Properties," Macromolecules 25, 6195-6204 (1992)

[14] J.T. Koberstein and L. M. Leung, "Compression-Molded Polyurethane Block Copolymers. 2. Evaluation of Microphase Compositions," Macromolecules 25, 6205-6213 (1992)

[15] J.T. Koberstein and R. S. Stein, "Small-Angle X-Ray Scattering Studies of Microdomain Structure in Segmented Polyurethane Elastomers," Journal of Polymer Science: Polymer Physics Edition, Vol. 21,1439-1472 (1983)

[16] J.T.Koberstein and R. S. Stein, "Small-Angle Light Scattering Studies of Macrophase Separation in Segmented Polyurethane Block Copolymers," Polymer, 25, 171 (1984)

[17] J.T. Koberstein, Irena Gancarz, and T. C. Clarke, "The Effects of Morphological Transitions on Hydrogen Bonding in Polyurethanes: Preliminary Results of Simultaneous DSC-FTIR Experiments," J. Polymer Science: Part B: Polymer Physics, 24, 2487-2498 (1986)

[18] M. A. Hood, B. B. Wang, J. M. Sands, J. J. La Scala, F. L. Beyer, C. Y. Li Morphology control of segmented polyurethanes by crystallization of hard and soft segments; Polymer, 51: 2191-2198 (2010)

[19] M. Szycher, "Biostability of Polyurethane Elastomers: A Critical Review”, J. Biomater Appl., 3: 297-402 (April 1988)

[20] R. J. Zdrahala and I. J. Zdrahala, "Biomedical Applications of Polyurethanes: A Review of Past Promises, Present Realities, and a Vibrant Future," J. Biomater Appl., 14: 67-90 (July 1999)

[21] H. Meng and J. Hu, "A Brief Review of Stimulus-active Polymers Responsive to Thermal, Light, Magnetic, Electric, and Water/Solvent Stimuli," J. Intelligent Material Systems and Structures, Vol. $21,859-885$ (June 2010)

[22] S. J. Hong, W-R Yu, and J. H. Youk, "Two-Way Shape Memory Behavior of Shape Memory Polyurethanes with a Bias Load," Smart Mater. Struct. 19, 03502, 1-6 (2010)

[23] S-H Hsu, S. Huang, Y. Y. Lin, K. W. Lem, D. S. Lee, J. Material Chemistry B, "Synthesis of Water-Dispersible Zinc Oxide Quantum Dots with Antibacterial Activity and Low Cytotoxicity for Cell Labeling," Nanotechnology 24, 475102 (2013)

[24] K. W. Lem, J. R. Haw, S. Curran, S. E. Sund, C. Brumlik, G. S. Song, D. S. Lee, " Effect of Hard Segment Molecular Weight on Concentrated Solution and Bulk Properties of Ether Based Thermoplastic," Nanoscience and Nanoengineering, 1(1): 71-88 (2013)

[25] K. W. Lem, D.S. Lee, J.R. Haw, G. S. Song, S. Curran, S. E. Sund, Z. Iqbal, and C. Brumlik, "Role of Hard Segment Induced Nanosized Domain on Dilute Solution Properties of Ether Based Thermoplastic Polyurethanes", NSTI-Nanotech 2011 (Proceeding), (1) 624 (2011) 
[26] K. W. Lem, D.S. Lee, J.R. Haw, G. S. Song, S. Curran, S. E. Sund, Z. Iqbal, and C. Brumlik, "Role of Hard Segment Induced Nanosized Domain on Concentrated Solution Properties of Ether Based Thermoplastic Polyurethanes", NSTI-Nanotech 2011 (Proceeding), (1) 60 (2011)

[27] S. Curran, K.W. Lem, S. E. Sund, and M. Gabriel, "Six Sigma Design - An Overview of Design for Six Sigma (DFSS)," Encyclopedia of Chemical Processing (ed. S. Lee), Marcel Dekker, NY (2006).

[28] K.W. Lem, S. Curran, S. E. Sund, and M. Gabriel, "Thermosets - Materials, Processes, and Waste Minimization," Encyclopedia of Chemical Processing (ed. S. Lee), Marcel Dekker, NY (2006).

[29] S. Brauer, K.W. Lem, and J.R. Haw, "The Markets for Soft Nanomaterials: Cosmetics and Pharmaceuticals", Presented in Nano and Green Technology Conference 2009; Nov 17-19 (2009)

[30] K. W. Lem, D. H. Nguyen, H. N. Kim, D. S. Lee, "Preparation and Characterization of the Transparent Hybrids of Silicone Epoxy Resin and Titanium Dioxide Nanoparticles via Sol-Gel Reactions," Journal of Nanoscience and Nanotechnology, 11(8), $7202-7205$ (2011)

[31] K. W. Lem, S-H. Hsu, D. S. Lee, Z. Iqbal, S. E. Sund, S. Curran, C. Brumlik, A. Choudhury, D. S-G. Hu, N. Chiu, R. C. Lem and J. R. Haw., "Waste Minimization for the Safe Use of Nanosilver in Consumer Products - Its Impact on the Eco-Product Design for Public Health," in "Public Health Epidemiology, Environmental and System Issues" (ed. J. Maddock), In-Tech Open Publication (May, 2012)

[32] K. W. Lem, A. Choudhury, A. A. Lakhani, P. Kuyate, J. R. Haw, D. S. Lee, Z. Iqbal, C.J. Brumlik "Use of Nanosilver in Consumer Products," Recent Patents in Nanotechnology, 6 (2012).

[33] K. W. Lem, J. R. Haw, D. S. Lee, C. Brumlik, S. E. Sund, S. Curran, P. Smith, S. Brauer, and D. Schmidt "Effect of Size on Properties of Nano-Structured Polymers - Transition from Macroscaling to Nanoscaling", Polymer Nanotechnology (Proceeding), NSTI-Nanotech 2010, 1(6), 889 (2010)

[34] K. W. Lem, J.R. Haw, D.S. Lee, Z. Iqbal, A. Salama, R. Senthil Kumaran, S. Sund, S. Curran, C. Brumlik, and A. Choudhury, "Nano Silver-Why It is still so Hot Now?", NSTI-Nanotech 2011 (Proceeding), (3) 557 (2011)

[35] K. W. Lem, J. R. Haw, D. S. Lee, C. Brumlik, S. E. Sund, S. Curran, P. Smith, S. Brauer, and D. Schmidt, "Nano Silver Why It is so Hot Now?" Nanoparticle Synthesis \& Applications (Proceeding), NSTI-Nanotech 1 (3) 391 (2010)

[36] J. W. Qian, M. Wang, Han D. L., R. S. Cheng, “A Novel Method for Estimating Unperturbed Dimension $[\eta] \theta$ of the Polymer from the measurement of its $[\eta]$ in a Non-Theta
Solvent,” European Polymer Journal, 37, 1403 (2001)

[37] C. D. Han, Rheology and Processing of Polymeric Materials (Vol. 1 \& 2) Oxford University Press (2007).

[38] L. H. Sperling, "Introduction to Physical Polymer Science, $4^{\text {th }}$ ed, Wiley-Interscience, (2006) page 476.

[39] C.A. Prestidge and Th.F. Tadros, "Viscoelastic Properties of Aqueous Concentrated Polystyrene Dispersions Containing Grafted Poly(Ethylene Oxide) Chains.” J. Colloid and Interface Sci., 124, 660-665 (1988)

[40] G. L. Flickinger, I. S. Dairanieh; C. F. Zukoski, "The rheology of aqueous polyurethane dispersions," J. Non-Newtonian Fluid Mech. 87, 283-305 (1990)

[41] C. D. Han and K. W. Lem "Chemorheology of Thermosetting Resins. IV. The Chemorheology and Curing Kinetics of Vinyl Ester Resin," Journal of Applied Polymer Science, 29,1879-1902 (1984)

[42] H. H. Winter and F. Chambon, "Analysis of Linear Viscoelasticity of a Crosslinking Polymer at the Gel Point," J. Rheol. 30, 367 (1986).

[43] C. M. Kok and A. Rudin, "Prediction of Osmotic Pressures of Polymer Solutions,” J. Appl. Polym. Sci., 26, 3575 (1981)

[44] C. M. Kok and A. Rudin, "Prediction of Second Virial Coefficients from Intrinsic Viscosities," J. Appl. Polym. Sci., 26, 3583 (1981)

[45] C. M. Kok and A. Rudin, "Prediction of Flory-Huggins Interaction Parameters from Intrinsic Viscosities," J. Appl. Polym. Sci., 27, 353 (1981)

[46] S. L. Shmakov, "Comments on The Paper "A Novel Method for Estimating Unperturbed Dimension $[\eta] \theta$ of the Polymer from the measurement of its $[\eta]$ in a Non-Theta Solvent, by J.W. Qian et al., Eur. Polym. J., 37, 1403 (2001),", European Polymer Journal 40, 1255 (2004)

[47] S. G. Kim, D. S. Lee, "Effect of Polymerization Procedure on Thermal and Mechanical Properties of Polyether Based Thermoplastic Polyurethanes," Macromolecular Research, 10(6), 365-368 (2002)

[48] V. K. Nguyen, M. J. Li, and D. S. Lee, "Effects of Hard Segment Length on Solution Viscosities of Ether Based Polyurethanes," Unpublished Data (2005)

[49] H. C. Beachell and J. C. Peterson, "Dilute Solution Properties of a Polyurethane. 1. Linear Polymers," J. Polym. Sci., Part A-1, 7, 2021-2029 (1969)

[50] R. R. Klimpel, "Introduction to Chemicals Used in Particle Systems," NSF Engineering Research Center for Particle Science \& Technology, University of Florida, p. 29, Fig 20. (1997) 